\title{
Using counterfactuals to display facts - the case of satirical humor
}

\author{
Adi Maslo \\ Džemal Bijedić University of Mostar
}

\begin{abstract}
Satire has not been given the humorologists' attention to an extent that would do justice to the amount of humor satire actually holds. Therefore, the intention of this paper is to shed light on satire as humorous discourse, with an emphasis on counterfactuals. Interestingly enough, counterfactuals oppose the actual state of affairs; rhetorically however, they show potential to reveal the truth. Political satire is an area of conflict between truth and falsehood which is exactly why this type of satire is discussed in this paper. Tools from Cognitive Linguistics - framing and blending - are utilized to show to what extent counterfactuals are actually false and how they essentially contribute to satire. Examples of political satire are selected from Comedy Central's The Daily Show.
\end{abstract}

Key words: satire; counterfactuals; cognitive linguistics; framing; blending; The Daily Show.

\section{Introduction}

The 2005 Danish cartoons about Prophet Muhammad engendered a series of debates, laughter (at times), abhor among Muslim countries and communities, and even violent response. Danish newspaper Jyllands-Posten published 12 editorial cartoons which targeted the faith of Islam and different levels of censorship in the religion, as authors of the newspaper suggested. More important than the relatively ephemeral nature of the cartoons themselves are the questions they raised, one of them being - are there any boundaries to jokes?

The "cartoons crisis" dilemma can be explained by Lewis et al.'s (2006) notion of normative community, which, in the authors' conceptualization, means that every society has its own rules what can be joked about. In other words, one can joke only about the group s/he belongs to. Lewis et. al.'s normative community follows Killingsworth's (1992) global discourse community, a term which aims at likemindedness and other "special interests" and surpasses physical site. That is, the dissemination of satire is bound not by physical distance but by a lack of common values. Lewis et. al. (2006) therefore suggest that there are entities that are too sacred or important to find themselves in jokes, such are God, the Queen, the Holo- 
caust, the Pope, the Bible, Katrina, the President or the Prophet. Besides the fact that there have been jokes about most of the entities Lewis et. al. describe (if not all), more importantly, the "cartoons crisis" showed a failure on both sides - the authors of the cartoons, on one hand, failed to understand the aforementioned notions, while the ones that responded violently, on the other hand, took what was counterfactual for real. More simply speaking, what Jyllands-Posten authors drew was not Prophet Muhammed, the reason for it being that there is simply no real photograph recorded of him i.e. the cartoonists made the people believe that this was the Prophet, and they did. The entire controversy revolved around counterfactuals and their role in satire.

Satire serves as a comedic and pedagogic form uniquely suited to provoking critical reflection. Its ability to underscore the absurdity, ignorance, and prejudice of commonly accepted behavior by means of comedic critical reflection offers an especially potent form of public critique. (McClennen, 2011:1)

The question then arises - what does humor have to do with critique, why does critique have to be funny, and what exactly is funny in satire? Straightforward logic proposes that facts be explained in detail and counterarguments be presented in order to critically approach an issue. However, in satire, it is quite the opposite a blend of facts and "lies" arises from the entire discourse with counterfactuals being the most salient of mechanisms.

This paper first introduces blending and framing, two mechanisms in Cognitive Linguistics that are the foundation for both generating and understating satirical messages. Moreover, counterfactuals are seen as a major feature of satirical discourse.

\section{Blending and framing}

In short, blending (blending theory or conceptual integration theory), thoroughly discussed in Fauconnier \& Turner (2002), is a process of combining two (or more) mental spaces into a final "blend", which is an intersection of the two, and, besides their respective inputs in terms of contents, the blend generates new insights into the topic at hand. In order to understand blends more deeply mental spaces need to be explained. Fauconnier \& Turner (2002) define mental spaces as "small conceptual packets constructed as we think and talk, for purposes of local understanding and action". The implication of "small conceptual packets" is that understanding is listener bound i.e. the inputs s/he receives meet life experience, long term memory and background knowledge to eventually result in understanding, or rather, meaning making. Reading between lines, we can see that everybody makes slightly different understanding besides receiving the same information, that is, each listener aligns incoming information to her/his already existing knowledge, understanding and worldview. Furthermore, words that the listener receives are 
only a trigger to understanding. "Local understanding and action" refers to on-line language processing, that is, decoding (understanding or meaning making) the message in real time.

More technically speaking, satire has two mental input spaces. However, for the purposes of explaining satirical discourse through blending theory, the terms thesis and antithesis need to be introduced. Popper (1963) (cited in Simpson, 2003) argues that there is first some idea or theory or movement which may be called a 'thesis' which then produces an opposing idea or movement, realized through opposition, negation or contradiction, called an antithesis. Consequently, there arises a contradiction between thesis and antithesis, which is why we resort to synthesis as resolution to the incongruity that emerged from the thesis and antithesis. Synthesis is equal to emergent structure in blending theory (Fauconnier \& Turner, 2002) which implies that the blend results in insights that are not inherently found in either of the input spaces whereas thesis and antitheses are taken as broader terms potentially encompassing more than one mental input space each. In other words, the conceptual blending model for satire proposed in this paper takes thesis and antithesis to be superordinate terms for mental input spaces. The thesis introduces facts, that is, participants, circumstances, relationships etc. within a certain event we can call factual while the satirist's creative and humorous contribution is in the form of the antithesis, which is counterfactual.

(1) Jon Stewart1: "Russia is like a live action Grand Theft Auto."

To understand (1), we need to understand both the situation at hand and the nature of the video game mentioned. Part of the blend is its thesis which refers to the fact that a few days before the episode a meteor was visible in the Chelyabinsk region while a further fact is that footage of the meteor came from a dash cam. Mention of the famous video game franchise (GTA) is what makes the antithesis since there is no "live action GTA" i.e. Stewart is projecting an imaginary scenario. The blend created by connecting the thesis and antithesis bears insights up to then not mentioned (known). Such knowledge ensues solely from a creative blend of factual and counterfactual input spaces (thesis and antithesis). The Russia-GTA example implicitly comments on Russian society generally being inclined towards violence in the streets in particular. ${ }^{2}$ In order to correctly understand the GTA satire, one need be aware that the famous franchise is understood not just as a video game but also as a social phenomenon. The satirist's creative contribution in the form of antithesis establishes the satirical discourse. Meaning in (1) is generated through the mention of GTA in relation to Russia, in other words, it is expected for the listener to bring the analogy to an end by referring to his/her background knowledge on the GTA franchise.

\footnotetext{
1 Former The Daily Show host.

${ }^{2}$ Which is why most drivers have dash cams. Accidentally one such cam recorded the meteor.
} 
While blends are a micro-context of a certain satirical discourse event getting to the point of the (satirical) humor, frames represent the macro-context background for it all. Frames are structures in our brain that are built up by experience and activated by speech. In other words, all words are defined relative to conceptual frames. When you hear a word, its frame is activated in your brain (Lakoff, 2004). For instance, the mention of "offside" triggers the entirety of the FOOTBALL frame while "knockout" activates the BOXING frame. Frames have the property of being relatively common among speakers of a language, culture depending of course. As Coulson (2001) points out, a lack of explicit context will trigger a default one in the head of the listener based on their personal experience/knowledge on the topic at hand. For example, upon hearing the news that a bank robbery happened, receivers of the news will most probably map their experience and assume that one or more young or mid-aged male persons were involved in the crime. This does not mean that e.g. older ladies cannot perform a robbery but common ${ }^{3}$ background knowledge does not prove that. The ROBBERY frame shows both the presence of frame structures in our brains and the interrelatedness of elements within every frame.

Rhetorically, a frame promotes its preferred perception by linking information to corresponding "culturally familiar symbols" present in the audience's knowledge structure "that guide individuals' processing of information" (Entman, 1993, cited in Wiesman, 2011). The GTA-Russia example from above shows that the mere mention of a culturally familiar symbol (GTA) suffices in order to channel the listener's decoding process. Simpson (2003) states that "getting the point" of a piece of satire is arguably to reach a "macro-resolution" for the text as a whole and not just to reach a series of localized resolutions for individual embedded jokes. This is the listener's meaning making process and the reason why conceptual blending and framing stand in a micro-macro relationship. These two tools from Cognitive Linguistics are present at everyday common speech and reasoning and even more interesting at the level of public discourse.

\section{Counterfactuals}

As elaborate as their inner workings are, counterfactuals are found in everyday "simple" language. Conditionals are one example of counterfactual use i.e. they may illustrate a situation that is desired or not, but at least not (yet) real(ized). Fauconnier \& Turner (2002) list the following conditionals:

(2a) If you'd only put yourself in my shoes, you'd have some sympathy, and if I could put myself in your shoes, I'd walk right back to me.

(2b) If cars were men, you'd want your daughter to marry this one.

\footnotetext{
${ }^{3}$ Culture specific, what one community has recorded in general in their experience.
} 
(2c) In France, Watergate would not have hurt Nixon.

(2d) Coming home, I drove into the wrong house and collided with a tree I don't have.

The reasonable question in this case is how it is possible that listeners even engage in decoding of such sentences/utterances. The conditionals given in (2a-d) show if-sentences and negation as grammatical structures that are most salient when it comes to counterfactuals. The question how receivers of such utterances ${ }^{4}$ partake in counterfactuals is twofold: their willingness to be part of something that is not "real", and the cognitive mechanisms they apply to decode such utterances. Firstly, as Coulson \& Pascual (2006) indicate, the speakers' goal in these examples is not to draw attention to the absurdities in the blend, but rather to the inferences and conceptualizations that emerge from them. Gettings (2007) indicates that sheer outrageousness or hyperbole is one of the clearest indicators that part of a fictional narrative is false or made up. Like jokes, satire is rewarding in a satisfactory sense which stems from the fact that not all is there in the utterance but listeners get to "build on" the speaker's joke and get a sense of accomplishment and involvement. They map their own life experience onto the proposed joke construct (because without the listener's understanding it is a failure) and hence get a somewhat personal version of the intended humorous message. Verbal irony has an element of unification because "the little intellectual dance we must perform to understand it brings us into a tight bonding with the ironist" (Booth, 1983:729).

Having answered the issue of listeners' motivation to partake in counterfactuals, there remains the question about the inner workings of counterfactual utterances, the cognitive mechanisms at the background of it all. Since this paper aims at political satire in specific, properties of the discourse at hand need be considered. Politics, we presuppose, is serious business hence the formal style of address and the general atmosphere around it. Naturally, we do not connect politics to humor or likewise, the more of a "transgression" then it represents when the satirist makes fun of politics and politicians.

The proposed Model of Satirical Political Humor (Figure 1) features truth and seriousness as starting points. These, however, get "filtered through" humorousness and counterfactuality eventually resulting in a satirical message. The filters mentioned are the satirist's creative contribution to the blend. They are not intended to distort the truth in any manner but their primary function is to raise public awareness through an entertaining form. Furthermore, such blends where fact and counterfactuality meet should also not be equated with fiction (Simpson 2003) i.e. what blends do is ultimately yield inferences that are relevant for reality (Fauconnier \& Turner, 2002) and not fiction. As an attempt to frame satire's truth-straddling nature as comprehensively as possible Simpson (2003) proposes the term referfictionality and explains that in instances of satirical humor referents are taken from "the"

\footnotetext{
${ }^{4}$ This paper focuses on on-line language processing thus the inclination to use "utterance" rather than "sentence".
} 
world of external nature while semantic propositions and narrative actions attached to those referents may be utterly fictional. In other words, the satirist deals with real "characters" whilst putting them into imagined "scenarios" however remaining faithful to the satirical message in general.

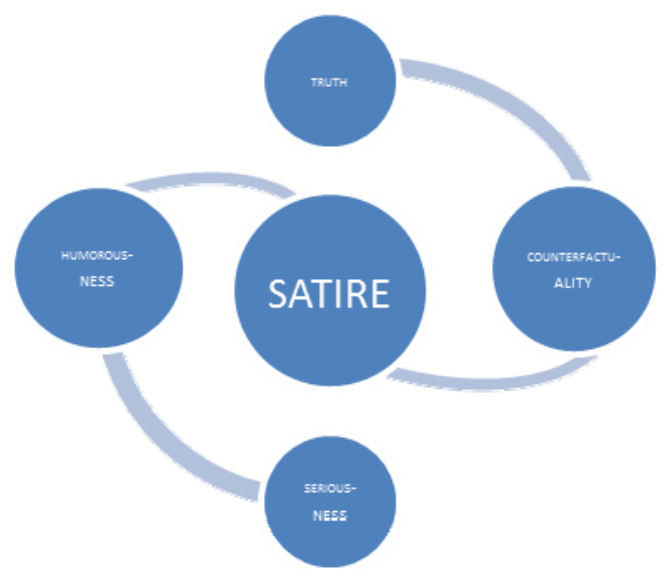

Figure 1: Model of Satirical Political Humor

\subsection{Counterfactuals in political satire}

Satire cannot function without a standard against which readers can compare its subject [...] The satirist, either explicitly or implicitly, tries to sway us toward an ideal alternative, toward a condition of what the satirist believes should be. It is assumed that the satirist has our best interests at heart and seeks improvement or reformation. Whether that standard is incontrovertibly right does not really matter. But what does matter is that the satirist and the reader share a perception of that standard. (Quintero, 2007:3)

The satirist's judgment is not completely arbitrary as it may seem. While her/his counterfactual input stems from personal creativity, the benchmark against which the critique is measured is the notion of normative community. Namely, as members of a society themselves, satirist have the right to "speak truth to power" and, more importantly, they know what is and what is not, what the "ideal alternative" of the community at hand is and who is responsible for not being so. The satirist calls for universal values such as freedom and justice but also for community specific values, the ones $s /$ he finds violated by the given politician/party. ${ }^{5}$

\footnotetext{
${ }^{5}$ Culture specific values should be understood as principles members of a community have adopted as a value e.g. accuracy and punctuality in the Japanese society or change and freedom of speech in the American society. Values such as obedience, discipline and discretion may be valued by some societies and completely opposed by others.
} 
Under the headline "Pimp my right", TDS authors disclose the Republicans' strategy on minorities in a humorous way.

(3) Jon Stewart: Let me break this strategy down. After pretending minorities didn't exist proved delusive, the Republican party has decided to physically go into these areas and engage 'person-to-person' or as that is known on the streets - talking [...] it worked for Kool cigarettes, why not for another company that doesn't care for the health of minorities?

Attributing seriousness to something banal (mere talking) builds up the satirical momentum already as well as the exaggerated account of it. The counterfactuality that arises from this example is that the Republican Party is equated with a company, one that does not care for the health of minorities on top. The mere mention of "company" in relation to a political party is enough for the listener to trigger the whole frame and map their experience onto the party. Aligning a political party with a cigarette brand transfers the negative effect onto the party. It is not exactly true that Republicans do not take care of the health of people, which is the counterfactual part, but neglecting minorities does harm people. Vice versa, the notion of "minorities" is normally not found in relation to cigarettes but it only serves to strengthen the notion that the Republican Party is a company of a harmful sort. To refer to the question of how listeners even want to engage in something counterfactual, it is worth mentioning that in such instances they are not even drawn to pose the question of factuality, the reason being obviously exaggerated account and the overall comedic TDS agenda. However, implications remain mapped onto the Republican Party thus it can be stated that the satirist channels the listeners' message decoding process to both make a rhetorical point and to entertain. In other words, TDS authors could have compared the Republican Party to, say, a destructive force or creature, still pertaining to the same feature of "harmfulness" and the humorous effect would have functioned as well, however, a frequent strategy of TDS is to introduce culture specific phenomena because they are kept in the listeners' memory and the sole mention of them activates the wished perception and automatically maps features onto the target. One positive side effect framing contributes to is language economy i.e. this compressed way of communicating features single words as representatives of the frames they belong to. Furthermore, it brings cognitive ease 6 to the listener if something familiar is presented as part of the antithesis. Another side effect that humorous/counterfactual blends bring into being is the issue of questionability. Curiously enough, in example (3) there is little doubt that listeners will remain without an understanding of the point even though they have not gone through the process of in-depth analysis of the nature of the Republicans-Minorities relationship. Fauconnier \& Turner (2002:57) explain this phenomenon:

\footnotetext{
${ }^{6}$ Nobel Prize in Economics and author Daniel Kahneman describes this phenomenon of the human reasoning process in his book entitled Thinking, Fast and Slow.
} 
In cases of step-by-step analysis, we do part of each step consciously, yet are left without a feeling that we understand the truth deeply, while in cases of blending, most of the analysis is done unconsciously, yet we can end up with a deeper satisfaction. We suggest that in the case of blending, at the moment of solution, the entire integration network is still active in the brain, even if unconsciously, while in the case of step-by-step analysis, at the moment of solution we have already lost most of the structure of the preceding steps.

The sense of understanding is anchored by the familiarity of the counterfactual input space (antithesis) which engenders deep sense of involvement in the discourse whereas the humorous effect entertains this idea. The simultaneous experience of appreciation and amusement makes the listener not go into a detailed analysis of what is said.

Another example of TDS introducing counterfactuality to shed light is when host John Oliver wonders how the Intelligence Surveillance Court, the body that gives permits for electronic surveillance, did not deny one of NSA's 1789 requests in one year.

(4) Oliver: It's basically American Idol with four Randy Jacksons.

Comparing a governmental body to an entertainment program already introduces a tension for its merging seriousness and humorousness (Figure 1). This redirects the listeners' attention towards the frame the satirist wants his (Oliver's) audience to conceptualize the target in, leading to the punch line in which the Agency is compared to the most lenient jury member of American Idol (accompanied with an illustration). The amount of laxity that the Agency in question exercises as with NSA's requests, which represents the truth, is paralleled with a counterfactual mental input space to help the audience grasp the proportion of the easefulness of the Court. The stronger the polarity between fact and counterfactual is the more efficient the satire will be. Simpson (2003) observes that satirical texts which exhibit only a marginal degree of opposition between factual and counterfactual mental input spaces 7 are obviously particularly prone to misfire. Furthermore, Attardo \& Raskin (1991) consider Script Oppositions the highest level within their concept of Knowledge Resources (within the General Theory of Verbal Humor) as they represent the key feature to humor construction. The farther apart the two mental input spaces the funnier the discourse will be. The shift (punch line) between two scripts is where the humorous effect emerges. Coulson (2001) calls this process Frame-shifting.

It is in the nature of satire to make use of counterfactual statements, moreover, it should be claimed that counterfactuals are the most essential part of satire. The conceptual integration of two scenarios into an absurd scenario in the blend is a common argumentative tactic (Coulson \& Pascual, 2006). Certainly absurd but not less educative (and entertaining) is when Jon Stewart comments on former US

\footnotetext{
${ }^{7}$ He calls them prime and dialect.
} 
President, Obama's statement where he claims that Congress does not allow him to close Guantanamo.

(5) Stewart: Congress - the legislative stone in America's urethra.

The counterfactuality is more than obvious in this example. Congress is no kind of stone, let alone a legislative one, nor does America have a urethra. However, Stewart brings forth the listeners' respective background knowledge, experience of the painfulness that is connected with having stone in one's urethra. The blend vividly illustrates the "blocking nature" of Congress in the given case. The counterfactual part of the blend is most salient, in other words, social actors and everything pertaining to them are "immersed" into the blend. What need be emphasized though is that blends are of ephemeral nature i.e. the statement in (5) certainly does not have any implications or consequences outside the joke itself. It is, however, true that the satirist (a satire TV show the more) creates a discourse where certain social actors, institutions or individuals, do have distinct traits attributed to them, where the repetitive mention of any of them in a specific context does create a frame of its own. For instance, in TDS Republican representatives do not enjoy considerable reputation because of their general attitude toward, say, a democratic nation.

The tension between thesis and antithesis should not be taken for granted. Even we believe, as already mentioned, that the satirist has our best interests at heart, the notion of the thesis is not a clear-cut case. Namely, the satirist highlights certain target's features depending on her/his worldview. From a frame semantics point of view, it is frequently possible to show that the same 'facts' can be presented within different framings, framings which make them out as different 'facts' (Fillmore, 1977). The worldview mentioned is aligned with the normative community principle, however, when targets are specific social actors ${ }^{8}$ there cannot be a unanimous opinion on each one. That is to say, the satirist decides what to "bring into" the factual frame as well. ${ }^{9}$

The following example is when Stewart criticizes Donald Rumsfeld's critique on (former) President Obama:

(6) Stewart: Rumsfeld is German for "promoting a narrative because it fits your hopes and what you want to be the case". It's the rare German word that is actually shorter than the thing it is describing.

The "literal falsity" as Fauconnier \& Turner (2002) put it is irrelevant to the reasoning process that such blends bear. In other words, the fact that (6) is counterfactual does not violate its credibility. In this example, Stewart plays upon the widely known feature of the German language in terms of long and descriptive words,

\footnotetext{
${ }^{8}$ TDS and well indended satire in general do not tend to target individuals but rather their functions and parties, along with their worldview.

${ }^{9}$ Besides the fact that the counterfactual mental input space is completely the satirist's.
} 
just that he twists it. The fact that "Rumsfeld" sounds German enough suffices for the counterfactual "definition", a definition Stewart needed to assess Rumsfeld's critique on Obama. Counterfactuals very frequently result in a funny way of political critique where the obvious counterfactuality stands as a mitigating device thus lessening the possibility of offense. [H] umour [...] offers a "way out" in discourse because it allows a humorist to take back what he or she says (Simpson 2003). TDS identifies itself as "fake news" which is they take the "way out", the logic behind being "we're just fake news, if you want real news go to serious media" ${ }^{10}$ In other words, satire itself depends on making the audience aware that counterfactuals play a major role there, otherwise it is certainly destined to misfire.

\section{Conclusion}

Politics is serious business and humor quite the opposite, thus making fun of political parties and figures is a delicate job. Straightforward logic dictates that we should display all facts and come to conclusion based on them. What political satire shown in the examples does is exactly the opposite. Counterfactuals are used in combination with facts to bring forth the truth in an amusing fashion. The brevity of blends and the fact that they are packed with intertwined factual-counterfactual information makes them appealing to the listener. Authors of TDS pick out either culturally recognizable phenomena or common collective experience/emotions for their antitheses thus creating a sense of listeners' involvement in the joke, and a sense of togetherness with the satirist. Blends with counterfactuals as the satirist's creative contribution to the discourse both inform/educate and entertain, the result being implications for the factual world, that is to say, counterfactuality is used to show the extent of political incoherence, propaganda or lack of credibility and put them into a form that is understandable, close to the listeners' experience and amusing (on top). No intention to distort the truth is there on the satirist's part, proof for it being that they make the counterfactuality that much obvious, reaching the level of absurdity at times. In conclusion, not only are counterfactuals a part of political satire but an essential one, carrying truth-revealing potential and amusing the listeners.

\section{References}

Attardo, Salvatore, Victor Raskin (1991). Script theory revis(it)ed: joke similarity and joke representation model. Humor, 4:3-4: 293-347.

\footnotetext{
10 A survey conducted by the Pew Research Center in 2004 showed that $61 \%$ of TV viewers that are under the age of 30 look for relevant news from politics in late-night humorous TV-news like TDS (cited in McClennen 2011). This shows that humorous, "fake news" are to some extent taken seriously.
} 
Booth, Wayne C. (1983). The Rhetoric of Fiction. Chicago: The University of Chicago Press

Coulson, Seana (2001). Semantic Leaps: Frame-Shifting and Conceptual Blending in Meaning Construction. Cambridge: Cambridge University Press.

Coulson, Seana, Esther Pascual (2006). For the sake of argument: Mourning the unborn and reviving the dead through conceptual blending. Annual Review of Cognitive Linguistics 4: 153-181.

Fauconnier, Gilles, Mark Turner (2002). The Way We Think. New York: Basic Books.

Fillmore, Charles (1977). Scenes-and-frames semantics. Zampolli, Antonio, ed. Linguistic Structures Processing. Amsterdam: North Holland, 55-82.

Gettings, Michael (2007). The fake the false and the fictional: The Daily Show as news resource. Holt, Jason, ed. The Daily Show and Philosophy: Moments of Zen in the Art of Fake News. Oxford: Blackwell Publishing, 16-28.

Hess, Aaron (2011). Purifying laughter: Carnivalesque self-parody as argument scheme in The Daily Show with Jon Stewart. Goodnow, Trischa, ed. The Daily Show and Rhetoric: Arguments, Issues, and Strategies. New York: Lexington Books, 93-112.

Killingsworth, M. Jimmie (1992). Discourse communities - local and global. Rhetoric Review 11.1: $110-122$.

Lakoff, George (2004). Don't Think of an Elephant! Know Your Values and Frame the Debate. White River Junction: Chelsea Green Publishing.

Lewis, Paul, Christie Davies, Giselinde Kuipers, Rod Martin, Elliott Oring, \& Victor Raskin (2008). The Muhammad cartoons and humor research: A collection of essays. Humor - International Journal for Humor Research 21.1: 1-46.

McClennen, Sophia A. (2011). America According to Colbert: Satire and Public Pedagogy. New York: Pelgrave Macmillan.

Quintero, Ruben (2007). A Companion to Satire. Oxford: Blackwell Publishing.

Simpson, Paul (2003). On the Discourse of Satire. Amsterdam: John Benjamins.

Wiesman, Penina (2011). We frame to please: A preliminary examination of The Daily Show's use of frames. Goodnow, Trischa (eds.) The Daily Show and Rhetoric - Arguments, Issues and Strategies. New York: Lexington Books, 131-151.

Author's address:

XI ul. br. 36, 88000 Mostar

Bosnia and Herzegovina

E-mail: adi.maslo@unmo.ba

Received: September 5, 2017

Accepted for publication: October 27, 2017 